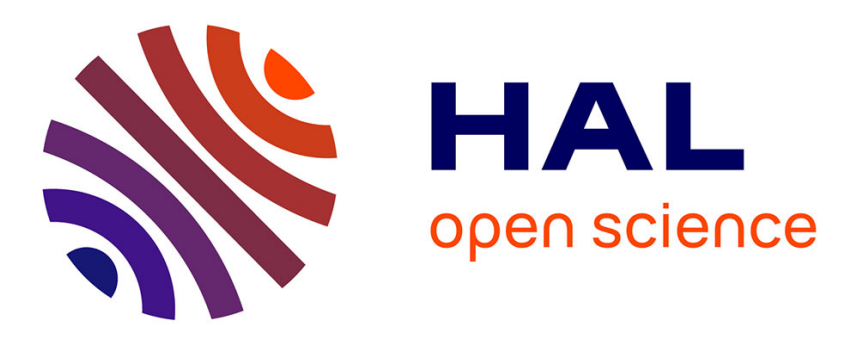

\title{
Nuclear background effects on plasma diagnostics for megajoule class laser facility
}

\author{
A. Rousseau, S. Darbon, P. Paillet, Sylvain Girard, J.L. Bourgade, Melanie \\ Raine, O. Duhamel, Vincent Goiffon, P. Magnan, A. Chabane, et al.
}

\section{- To cite this version:}

A. Rousseau, S. Darbon, P. Paillet, Sylvain Girard, J.L. Bourgade, et al.. Nuclear background effects on plasma diagnostics for megajoule class laser facility. Target Diagnostics Physics and Engineering for Inertial Confinement Fusion II, Aug 2013, San Diego, United States. pp.885004, 10.1117/12.2024005 . ujm-00871773

\section{HAL Id: ujm-00871773}

\section{https://hal-ujm.archives-ouvertes.fr/ujm-00871773}

Submitted on 30 Mar 2020

HAL is a multi-disciplinary open access archive for the deposit and dissemination of scientific research documents, whether they are published or not. The documents may come from teaching and research institutions in France or abroad, or from public or private research centers.
L'archive ouverte pluridisciplinaire HAL, est destinée au dépôt et à la diffusion de documents scientifiques de niveau recherche, publiés ou non, émanant des établissements d'enseignement et de recherche français ou étrangers, des laboratoires publics ou privés. 


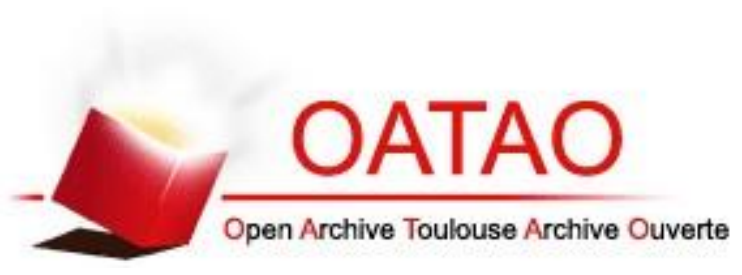

\section{Open Archive Toulouse Archive Ouverte (OATAO)}

OATAO is an open access repository that collects the work of Toulouse researchers and makes it freely available over the web where possible.

This is an author-deposited version published in: http://oatao.univ-toulouse.fr/ Eprints ID: 11001

To cite this document: Rousseau, A. and Darbon, S. and Paillet, P. and Girard, S. and Bourgade, J. L. and Raine, M. and Duhamel, O. and Goiffon, Vincent and Magnan, Pierre and Chabane, A. and Cervantes, Paola and Hamel, M. and Larour, J. Nuclear background effects on plasma diagnostics for megajoule class laser facility. (2013) In: SPIE Optics+Photonics, 25 August 2013 - 29 August 2013 (San Diego, California, United States).

Any correspondence concerning this service should be sent to the repository administrator: staff-oatao@inp-toulouse.fr 


\title{
Nuclear background effects on plasma diagnostics for megajoule class laser facility
}

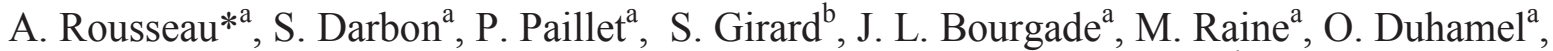

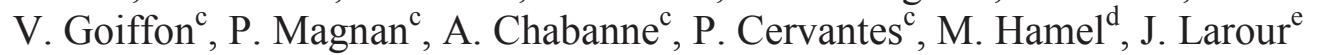

${ }^{a}$ CEA, DAM, DIF, F-91297 Arpajon, France; ${ }^{b}$ Lab. Hubert Curien, UMR CNRS 5516, 18 rue du pr. Benoît Lauras, F-42000 Saint-Etienne, France; ' ${ }^{\circ}$ Université de Toulouse, ISAE, 10 avenue E. Belin, F-31055, Toulouse, France; ${ }^{\mathrm{d} C E A}$, LIST, Lab. Capteurs et Architectures Electroniques, F-91191, Gif-sur-Yvette Cedex, France; ' Lab. de Physique des Plasmas, UMR 7648, Ecole Polytechnique, UPMC, CNRS, 91128 Palaiseau, France

\begin{abstract}
Estimating the vulnerability is a key challenge for plasma diagnostics designed to operate in radiative background associated with megajoule class laser facilities. Since DT shots at OMEGA laser facility reproduce the perturbing source expected during the first 100 nanoseconds of a typical DT shot realized at National Ignition Facility (NIF) and Laser MegaJoule facility (LMJ), vulnerability of diagnostic elements such as optical relays or optical analyzers were experimentally studied and, if necessary, hardening approaches have been initiated to authorize their use at higher radiative constraints. Other facilities such as nuclear reactor or accelerator have been also used to estimate vulnerability issues as radiation induced emission of glasses or damage in multilayer coatings.
\end{abstract}

Keywords: ICF, Laser MegaJoule, multilayer coatings, damage, optical relay, scintillator, vulnerability

\section{INTRODUCTION}

ARTEMIX, Architecture with Radio-Tolerance for high Energy Microscopy In X-ray bandwidth, is a fundamental tool for diagnosing the core size and the shape of the DT-target in the 5-100 keV band in complement of neutron imaging system $[1,2]$ in a harsh environment increasing with the progression of fusion experiments.

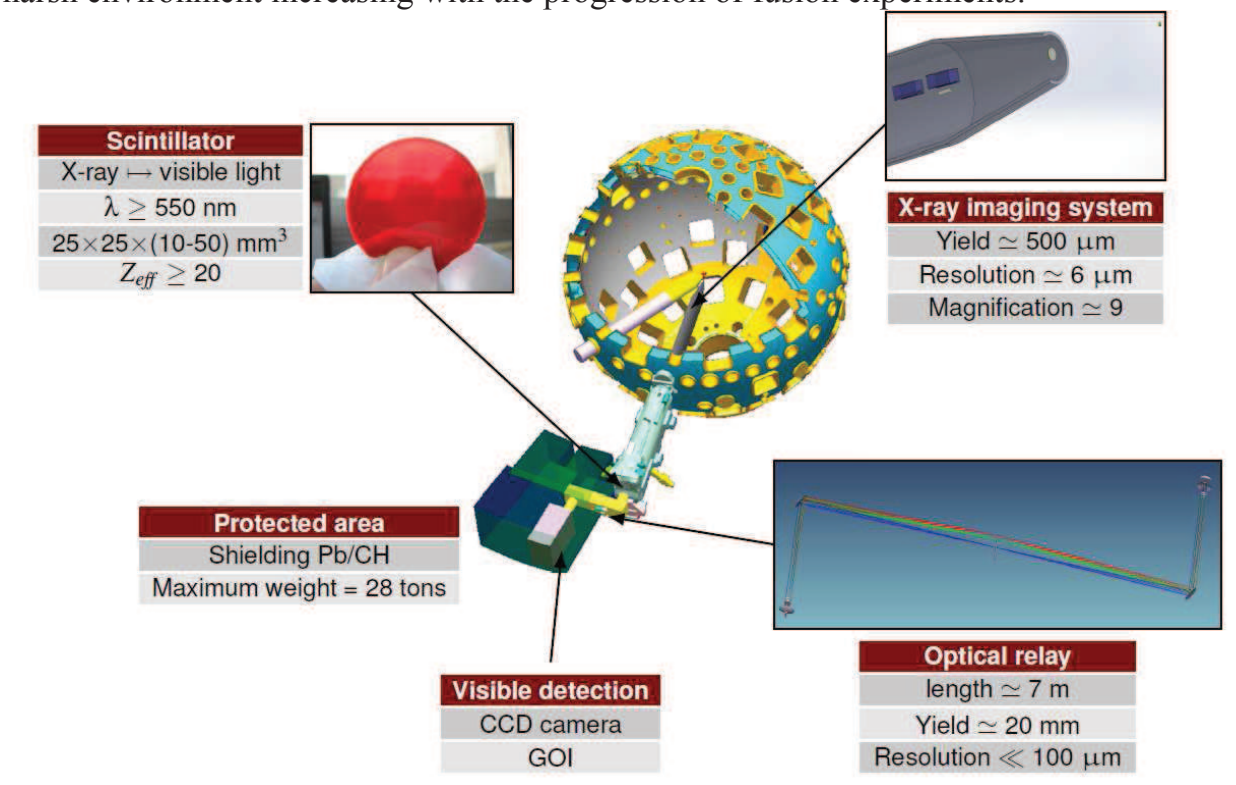

Figure 1. Artemix architecture for diagnosing the core size and the shape of the DT microballoon. 
As illustrated in figure 1, its design takes into account constraints $[3,4]$ due to the specific nuclear background of a megajoule facility such as LMJ or NIF (see figure 2a).

Indeed, one way to protect the diagnostic from particles generated during the implosion consists in recording image in a shielded box in which background is significantly reduced [5]. The X-ray image of the core will be formed on a scintillator [6] through an X-ray optical system. The X-ray optical system itself consists of the association of an annular aperture and a bitoroidal mirror microscope with multilayer coating. Then the visible light induced by the scintillator is easily transferred through an optical relay to shielded box and then focused on a detector. Each element of the diagnostic might be affected by particles generated when fusion reactions occurred. Thus, the paper focuses more specifically on X-ray imaging system and optical relays vulnerability because vulnerability of recording device and mitigation techniques have been already presented $[7,8,9,10]$.

\section{METHODOLOGY FOR VULNERABILITY INVESTIGATIONS}

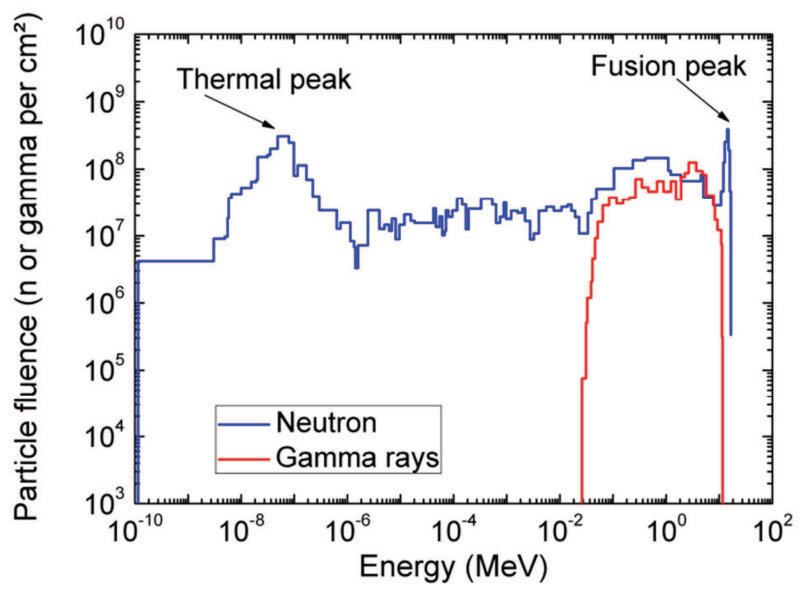

(a)

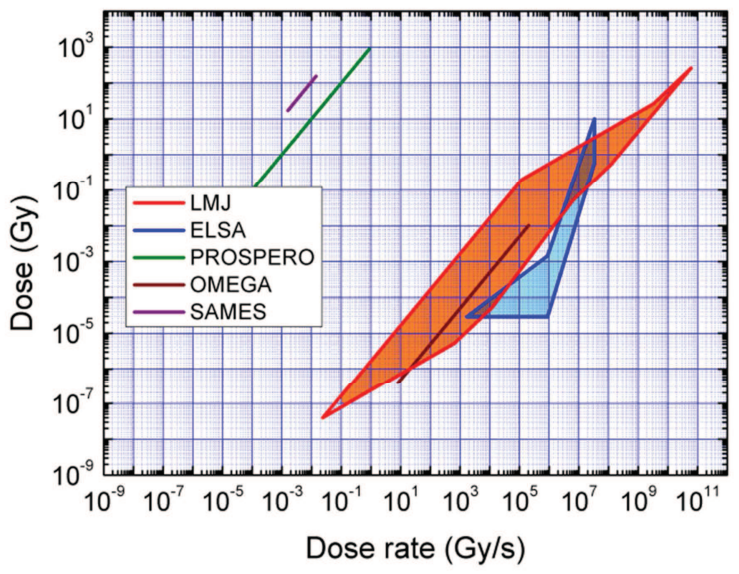

(b)

Figure 2.Methodology for vulnerability investigation (a) simulated spectrum of nuclear background induced by $1.10^{16}$ neutron Yield at 4 meters from target chamber center. This spectrum will be reproduced using the facilities presented in (b).

To lead vulnerability investigation, experimental studies cannot be done in megajoule facilities due to limited access. Consequently, an alternative approach is based on the use of successive irradiation facilities such as accelerator or reactor to reproduce as well as possible the LMJ constraints. Thus, the nuclear background which spectrum is illustrated in figure 2.a is reproduced by parts with three installations. Gamma ray spectrum is simulated by ELSA [11] accelerator with $18 \mathrm{MeV}$ electrons which produce X-ray by Bremsstrahlung effect when impinging tantalum target. PROSPERO [12] reactor and SAMES accelerator simulate respectively the thermal part of neutron spectrum thanks to fission neutrons and the energetic part with fusion ones. As illustrated in figure 2.b, these facilities can only reproduce equivalent dose to LMJ. Last but not least, since the DT shots at the OMEGA facility (university of Rochester) reproduce the perturbing source expected during the first $100 \mathrm{~ns}$ on megajoule-class laser facilities, this facility can be used to study the survivability of diagnostic elements.

\section{VULNERABILITY OF X-RAY IMAGING SYSTEM}

Multilayer coating is a key technique for broadband x-ray imaging at grazing incidence. Because it is based on an interferential structure due to periodic or non-periodic stack of high optical contrast materials such as W/SiC, multilayer coating is a vulnerable part of the X-ray imaging system.

Behavior of multilayers coating for X-ray bandwidth has been already studied when exposed to bright X-ray beam. Although fusion neutrons can generate recoil kernel propagating through the nanoscale structure, with respect to neutron or equivalent ion irradiation, stability of immiscible metals were mainly tested [13, 14]. In order to control multilayer stability for $\mathrm{W} / \mathrm{SiC}$ couple, two samples of mirror have been exposed to high neutron background on SAMES accelerator 
and PROSPERO reactor. Assuming the mirror position at 1 meter from the TCC, the neutron fluence in both facilities was as high as $1.10^{12} \mathrm{n} . \mathrm{cm}^{-2}$ which is equivalent to a neutron yield of $5.10^{18}$ neutrons on a megajoule facility. As such facilities deliver a mixed neutron and gamma field, a mirror has also been exposed to an 18 MeV X-ray beam on ELSA facility to distinguish neutron or gamma rays effects. One way to characterize mirror and identify irradiation damage consists in angular scans of samples for $8.048 \mathrm{keV}$ photon energy. Scans performed after irradiations were compared to reference one realized before irradiation as illustrated in figure 3. Because no modification of interferential function was observed for all irradiation facilities, we have experimentally guaranteed the robustness of W/SiC nanoscale coatings and validated their use on a megajoule nuclear background.

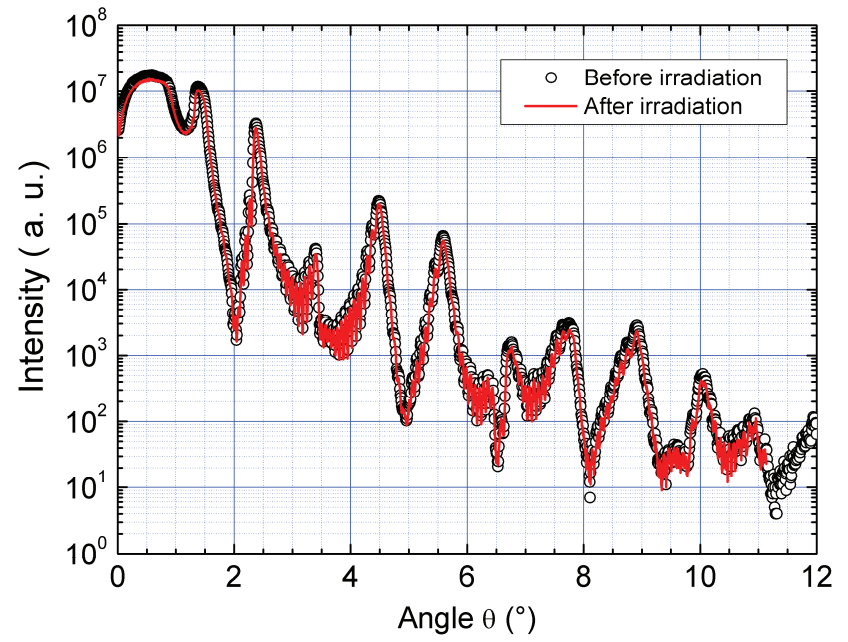

(a)

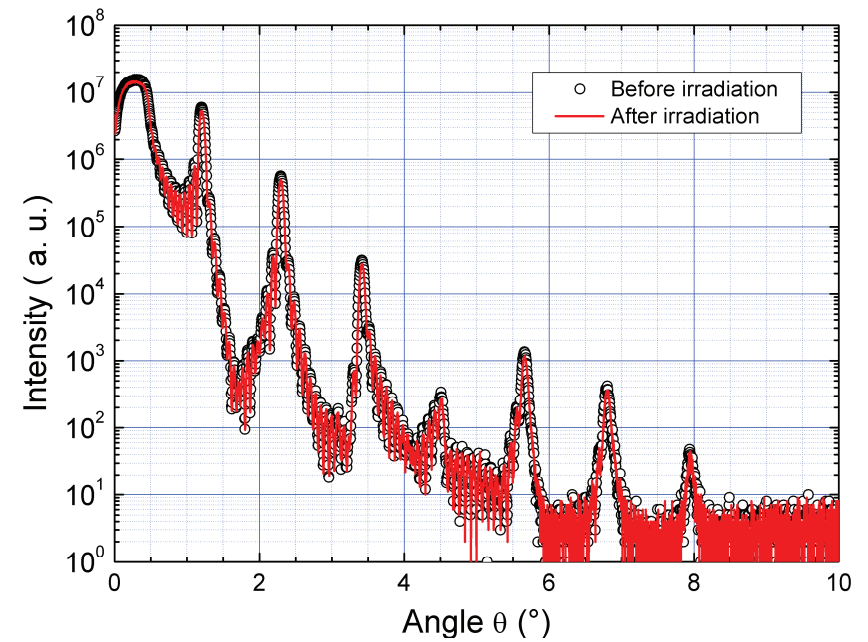

(b)

Figure 3.Characteristics of $\mathrm{W} / \mathrm{SiC}$ coating mirrors before and after irradiation on a nuclear facility. (a) When mirror is exposed to $1.10^{12} \mathrm{n} . \mathrm{cm}^{-2}$ on Prospero reactor. (b) When mirror is exposed to 0.75 Gy on ELSA accelerator.

Consequently, a new modeled broadband coating has been designed for $10-27 \mathrm{keV}$ photon energy. This specific bandwidth has been identified by hydrodynamics simulation and measurements [15] as one of interest to study denser and warmer plasma produced by ICF.

\section{VULNERABILITY OF OPTICAL RELAY}

Several processes can impact optical relay due to nuclear background. Among them, Radiation Induced Emission is one of major phenomena that can disturb image acquisition because of dynamic range loss on recording device.

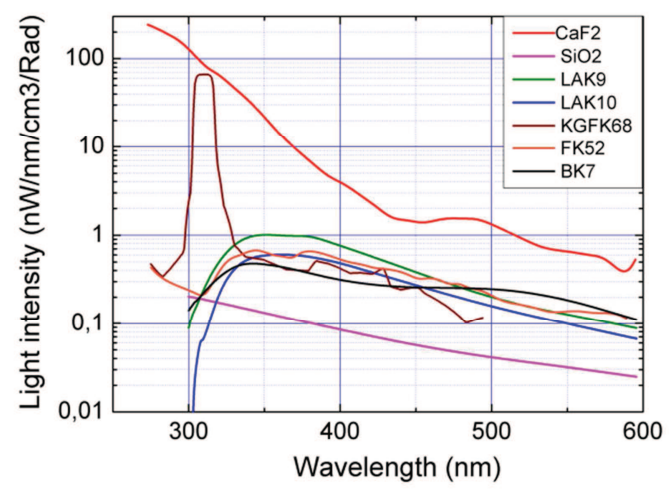

(a)

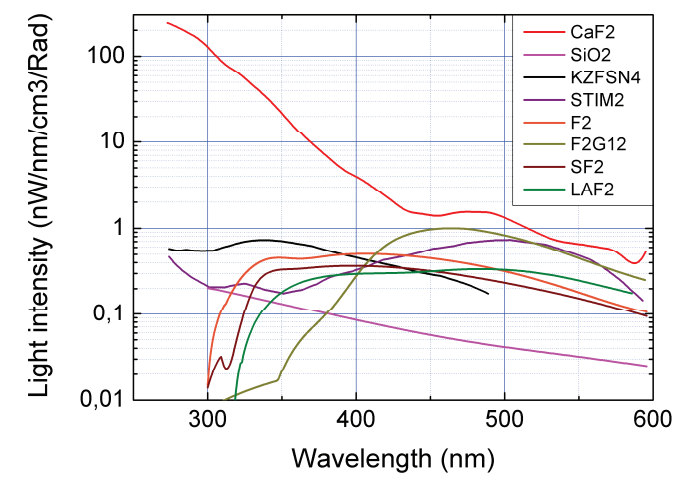

(b)

Figure 4. Scintillation spectrum measured on ELSA accelerator at $18 \mathrm{MeV}$ and normalized to dose and glass volume. (a) Measurements for crown glass samples. (b) Measurements for flint glass samples. 
Consequently, the very first step for designing an optical relay consists in studying glass scintillation under irradiation in order to identify and eliminate glass-based optics with high sensitivity to radiations.

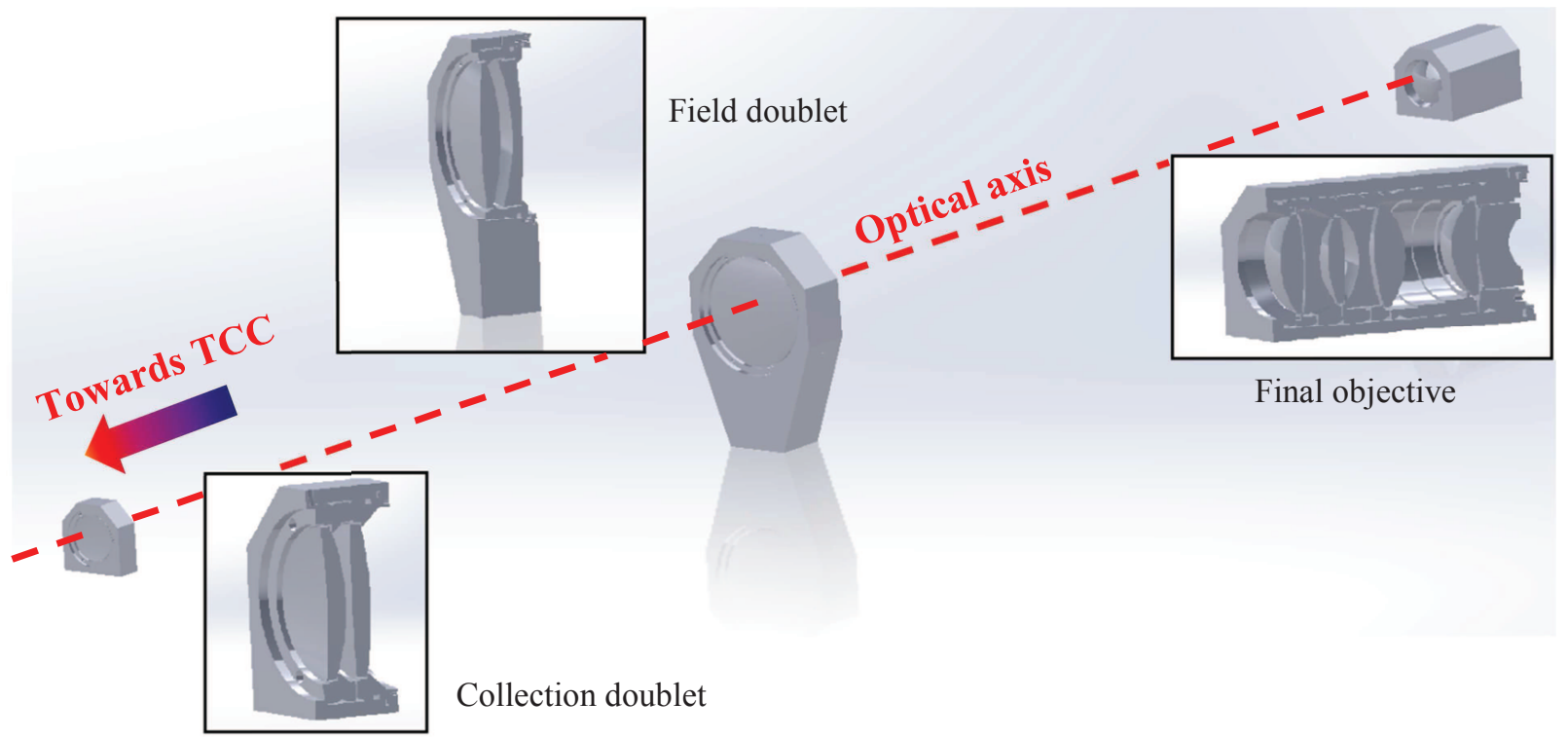

Figure 5. Principle of asymmetric optical relay designed for scintillation minimization.

That's the reason why scintillation spectra of several glass samples have been measured on ELSA facility. Because previous measurements [7] have shown that scintillation intensity increases linearly with glass volume, all data have been normalized by sample volume. Furthermore, assuming isotropic emission, that has been checked for cylindrical sample, spectrum has also been corrected by flux collection ratio corresponding to spectrometer characteristics and its measurement conditions so as to deliver absolute emission normalized to dose. As shown in figure 4, CaF2 has the highest level of scintillation under $18 \mathrm{MeV}$ beam. This glass will consequently not be used in image transport even if its optical dispersion allows chromatic aberrations correction. Commercial radiation resistant glasses such as F2G12, doped with cerium, are also good scintillators for wavelengths higher than $400 \mathrm{~nm}$. For other glasses, scintillation levels are quite equivalent except for pure silica which exhibits the lowest scintillation level.

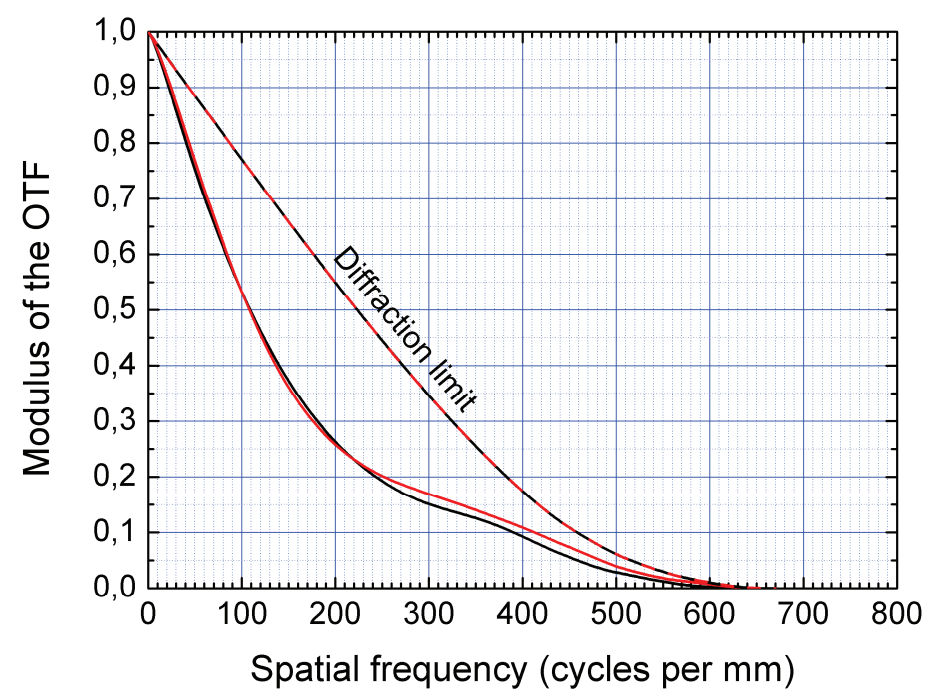

Figure 6. Optical Transfer Function of the asymmetric relay for tangential (black line) and sagittal (red line) plane. Diffraction limit is also illustrated. 
In consequence, a hardened design of optical relay will be asymmetric. Because dose decreases with distance from Target Chamber Center (TCC), glass volume must be minimized close to experimental chamber with pure silica preference for glass selected. A final objective with more glass volume will then reduce optical aberrations to reach high spatial resolution. An example of such design is given in figure 5 and a spatial resolution of 100 cycles per mm within a $20 \mathrm{~mm}$ field of view is expected as shown in Optical Transfer Function (OTF) illustrated in figure 6.

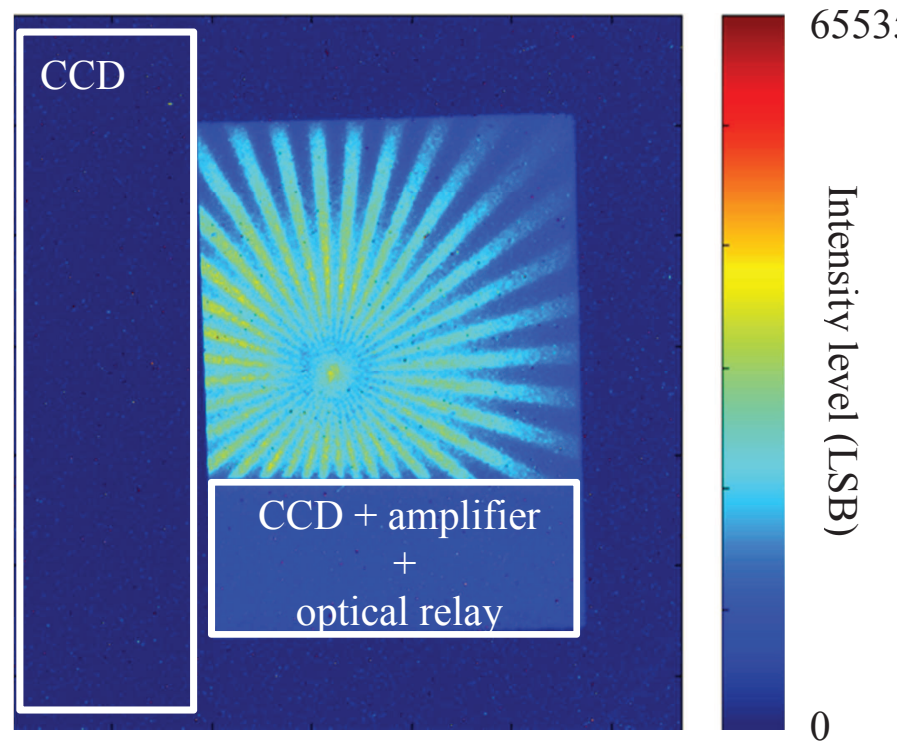

Figure 7. Example of background level generated under $10^{13}$ neutron yield on an optical analyzer and an optical fiber bundle as optical relay at $5 \mathrm{~m}$ from TCC.

The asymmetric relay is now under vulnerability test and will be compared to other optical relays such as a 2 meter long optical fiber bundle or 4 meter catadioptric relay using commercial Maksutov objectives. These devices have been exposed to high neutron yield on OMEGA facility. Its nuclear background leads to visible effects on the recording device which is a light amplifier and a cooled charge-coupled-device (CCD) camera as illustrated in figure 7.

Parasitic signal intensity can be quantified thanks to masks positioned between optical interfaces. As a result (figure 8.), parasitic light generated by optical relay is converted into CCD dynamic range reduction by quantification of histogram shifting. As previously [3, 7] observed for CCD camera and light amplifier, the dynamic range reduction appears to be directly proportional to the neutron fluence. The extreme sensitivity of the fiber bundle has been checked and extrapolation to NIF or LMJ fluence leads to complete failure of the diagnostic. On the contrary, the catadioptric relay because of a low glass volume generates a few quantity of light when exposed to irradiation. To see contribution in dynamic range for this specific relay, the optical gain of light amplifier must be maximized. Unfortunately, this kind of optical relay has poor optical qualities such as spatial resolution which reaches 20 cycles per mm.

As a conclusion, when vulnerability of the asymmetric relay will be confirmed, it will offer a good compromise between high spatial resolution needed for image quality and robustness under harsh nuclear background. 


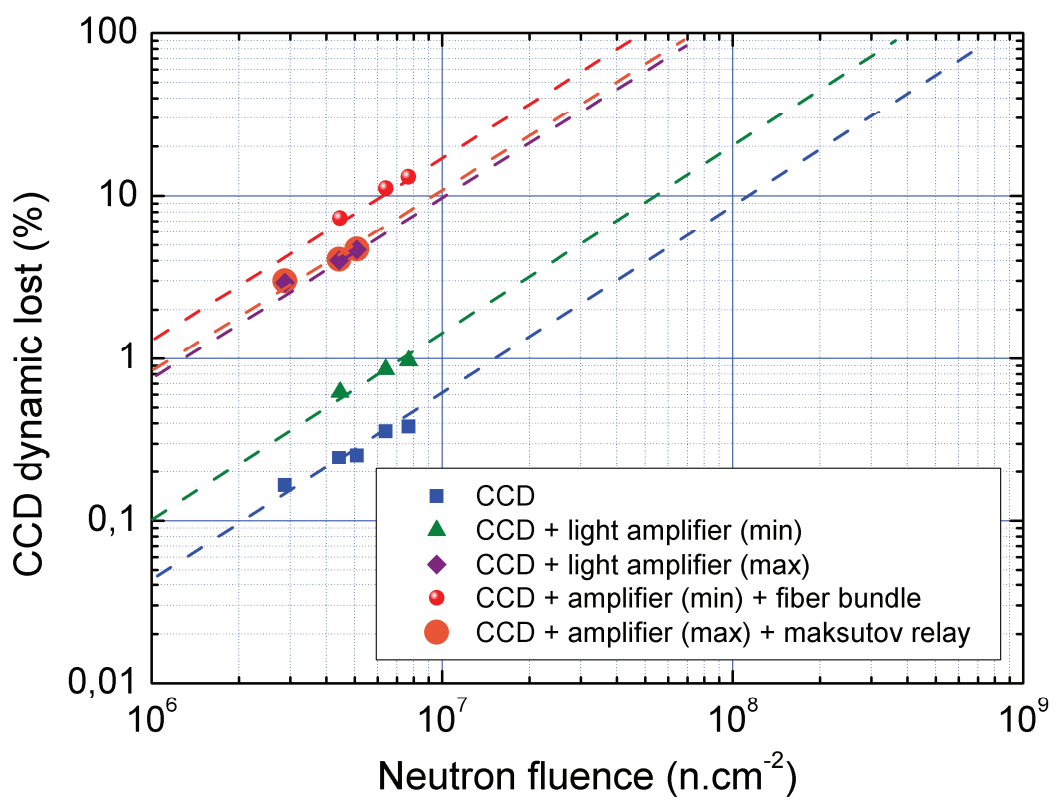

Figure 8. Parasitic signal intensity converted into the CCD dynamic range reduction for typical OMEGA neutron fluence.

\section{CONCLUSION}

The effects of neutron induced background on $\mathrm{W} / \mathrm{SiC}$ multilayer coating have been experimentally studied. For a typical fluence of $1.10^{12} \mathrm{n} . \mathrm{cm}^{-2}$ no change in reflectivity profile has been observed for X-ray mirrors. These non-periodic mirrors can consequently be applied to image the polychromatic X-ray plasma even if a large amount of neutrons are produced.

Vulnerability of optical relay has also been performed and has shown intense light generation of optical fiber bundle which leads to optical analyzer saturation. For robust concept, minimization of glass quantities is a very good choice as reveals low light level generation by catadioptric relay. But its intrinsic spatial resolution will reduce drastically diagnostic performance for image quality. The asymmetric designed relay will then constitute an alternative scheme for hardened optical relay because glass volume has been reduced close to target chamber center.

\section{ACKNOWLEDGEMENTS}

The authors are very grateful to all the staff, operators, and technicians of the OMEGA facility during the high neutron yield campaigns performed over these past years. The work performed by LLE personnel was supported by the U.S. DOE Office of Inertial Confinement Fusion under Cooperative Agreement No. DE-FC52-08NA28302, the University of Rochester, and the New York state Energy Research and Development Authority. The support of DOE does not constitute an endorsement by DOE of the views expressed in this article.

The authors wish to express their gratitude to all staff, operators, and technicians of PROSPERO reactor, ELSA and SAMES accelerator who performed irradiations.

\section{REFERENCES}

1. Merrill, F. E. et al., "The neutron imaging diagnostic at NIF," Rev. Sci. Instrum. 83, 10D317 (2012).

2. Didier, L et al., "Neutron imaging of ICF target plasmas," Rev. Sci. Instrum. 74, 1832 (2003).

3. Bourgade, J. L. et al., "New constraints for plasma diagnostics development to harsh environments of MJ class lasers," Rev. Sci. Instrum. 75, 4204-4212 (2004). 
4. Bourgade, J. L. et al., "Diagnostics hardening for harsh environment in Laser MegaJoule,” Rev. Sci. Instrum. 79, 10F301 (2008).

5. Song, P. et al., "Neutron radiation shielding for the NIF streaked X-ray Detector (SXD) Diagnostic," Fusion Science and Technoligy 52, 1035-1039 (2007).

6. Hamel. M. et al., "Preparation and characterization of highly lead-loaded red plastic scintillators under low energy xrays," Nucl. Instrum. Methods. Phys. Res. A 660, 57-63 (2011).

7. Rousseau, A. et al., "Vulnerability of optical detection systems to megajoule class laser radiative environment," Proc. SPIE 8439, Optical Sensing and Detection II, 84391F (2012).

8. Goiffon, V. et al., "Vulnerability of CMOS image sensors in megajoule class laser harsh environment," Optics Express, Vol. 20 pp.20028-20042, (2012).

9. Goiffon, V. et al., "Mitigation technique for the use of CMOS image sensors in Megajoule class laser radiative environment," IEE Electronics Letters, Vol. 48, p1338-1339, (2012).

10. Paillet, P. et al., "Hardening Approach to Use CMOS Image Sensors for Fusion by Inertial Confinement Diagnostics," Presented at NSREC, San Francisco (2013).

11. Chauchat, A. S. et al., "Construction of a Compton source for X-rays in the ELSA facility," Nucl. Instrum. Methods Phys. Res. A 608, S99-S102 (2009).

12. Morin, J. et al., "The PROSPERO and CALIBAN neutron irradiation facilities," Radiation and its Effects on Devices and systems, pp. 574-576 (1991).

13. Chen, Y. G. and al., "Irradiation-induced immiscible Mo-Cu system through multilayer technique," J. Appl. Phys. 82, 3815 (1997).

14. Milosavljević, M. et al., "Ion irradiation stability of Multilayered Al/TiN nanocomposites," J. Phys. D: Appl. Phys. 43, 065302 (2010).

15. Ma, T., "Imaging of high-energy x-ray emission from cryogenic thermonuclear fuel implosions on the NIF," Rev. Sci. Instrum. 83, 10E115 (2012). 